\title{
Expression change of PirB in mice retina after optic nerve injury
}

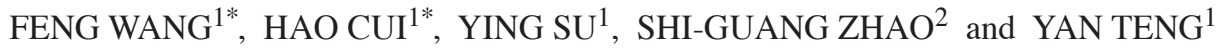 \\ Departments of ${ }^{1}$ Ophthalmology, and ${ }^{2}$ Neuroscience Surgery, \\ First Clinical College of Harbin Medical University, Harbin 150001, P.R. China
}

Received December 23, 2009; Accepted March 18, 2010

DOI: 10.3892/mmr_00000272

\begin{abstract}
The aim of this study was to observe the location of paired immunoglobulin-like receptor B (PirB) in the retina and to evaluate the expressive varieties of PirB in the retina of mice after optic nerve injury. In situ hybridization was used to observe the location of PirB mRNA in the retina of mice. Western blotting was used to analyze the levels of PirB protein in retina 7 days after optic nerve crush. Expression of PirB was located in the retinal ganglion cells of mice. The level of PirB protein increased significantly in the retina after optic nerve crush compared to the control group. PirB plays an important role in the inhibition of axonal regeneration after optic nerve injury. We conclude that the inhibition of PirB expression may enhance axonal regeneration after optic nerve trauma.
\end{abstract}

\section{Introduction}

Axons in the adult mammalian central nervous system (CNS) have a very limited capability to regenerate after injury. Regeneration failure has been attributed in part to proteins associated with CNS myelin, which appears to contain inhibitory molecules that actively block regeneration. Three myelin-associated proteins, the C-terminal of NogoA, Nogo66 $(1,2)$ myelin-associated glycoprotein (MAG) $(3,4)$ and Omgp (5), exert their effects via the Nogo receptor $(\mathrm{NgR})$ (6). However, it has been shown that genetic deletion of $\mathrm{NgR}$ does not relieve the chronic inhibition of neurite outgrowth by myelin inhibitors present as substrates. Furthermore, genetic deletion of $\mathrm{NgR}$ did not enhance the regeneration of corticospinal tract (CST) axons after dorsal hemisection (7), although some regeneration of raphespinal and rubrospinal tracts after spinal cord injury has been reported. Atwal et al (8) identified PirB as a potential target for axon regenera-

Correspondence to: Dr Ying Su, Department of Ophthalmology, First Clinical College of Harbin Medical University, Harbin 150001, P.R. China

E-mail:wfsym666@126.com

*Contributed equally

Key words: paired immunoglobulin-like receptor, optic nerve, axon, retina tion therapies and found that blockage of PirB enhances the axonal regeneration of CGNs. PirB is a necessary receptor for neurite inhibition by myelin extracts and, more specifically, by the myelin-associated inhibitors Nogo66, MAG and Omgp (8). However, the location of PirB and expessive varieties of PirB in the retina after optic nerve injury are unknown. In this study, the location of PirB in the retina was investigated, and the expression change of PirB in the retina of mice after optic nerve $(\mathrm{ON})$ injury was evaluated.

\section{Materials and methods}

Reagents. Pentobarbital sodium (Shanghai Biological Co., Shanghai, China), NgR antibody (Zymed Laboratories Inc., San Francisco, CA, USA), poly-lysine, phosphate buffer (Sigma, St. Louis, MO, USA), an in situ hybridization kit for PirB, PirB antibody, the streptavidin-biotin-peroxidase complex (SABC) (Boster Co., Wuhan, China), Hybond-P polyvinylidene difluoride (PVDF) membrane (Amersham Pharmacia Biotech, Piscataway, NJ, USA), goat anti-rabbit secondary antibody, an enhanced chemiluminescence kit (Santa Cruz Biotechnology, Santa Cruz, CA, USA) and anti-GAPDH antibody (Abcam Co., Cambridge, MA, USA) were used.

Equipment. Anatomic microscope (SZ-PT; Olympus, Tokyo, Japan), optic microscope (Olympus) and $40 \mathrm{~g}$ power ON forceps (Martins Instruments, Tullingen, Germany, donated by Professor Gu Zhao-bin, Gifu University of Japan) were used.

Animal grouping. The experimental group included the left eyes of 30 mice ( 8 or 12 weeks old) whose ON was crushed, and the normal control group consisted of the right eyes of mice whose ON was left untouched. The mice were sacrificed 7 days after ON crush.

Surgical procedure. Prior to ON crush, general anesthesia was induced in each animal with an intraperitoneal injection of $1 \%$ sodium pentobarbital solution ( $50 \mathrm{mg} / \mathrm{kg}$ body weight). A surgical microscope was used to visualize the ON, which was exposed through a superior temporal approach. The dural sheath of the ON was opened longitudinally, then the ON was then gently detached from the sheath and crushed $1 \mathrm{~mm}$ distal to the eyeball by $\mathrm{ON}$ forceps with $40 \mathrm{~g}$ of pressure for $9 \mathrm{sec}$. Injury to the ophthalmic artery was carefully avoided during the procedure. Nerve injury was verified by the appearance of a clearing at the crush site; the vascular integrity of the retina 
was verified by funduscopic examination after dilating the pupil with atropine. The left $\mathrm{ON}$ was crushed in the experimental group, while the right ON was left untouched in the control group.

Western blotting. Retina were prepared in extraction buffer containing $50 \mathrm{mM}$ Tris- $\mathrm{HCl}$ (pH 7.4), $150 \mathrm{mM} \mathrm{NaCl}, 1 \%$ Triton-100, 0.1\% SDS, $1 \mathrm{mM}$ EDTA, $1 \mathrm{mM}$ AEBSF, $20 \mu \mathrm{g} /$ $\mathrm{ml}$ aprotinin and $20 \mu \mathrm{g} / \mathrm{ml}$ leupeptin. Equal amounts of total protein $(10 \mu \mathrm{g})$ were separated by $10 \%$ SDS-PAGE and transferred to a Hybond-P polyvinylidene difluoride (PVDF) membrane. After blocking with 5\% non-fat dry milk in PBS and $0.1 \%$ Tween-20, membranes were probed with rabbit anti-PirB antibody (1:500) followed by incubation with a secondary antibody $(1: 1000)$. Visualization of the protein bands was performed using an enhanced chemiluminescence kit. Parallel Western blotting was probed with an anti-GAPDH antibody as a loading control. Band intensity was quantified using Quantity One 4.4.1 software (Bio-Rad).

Preparation for in situ hybridization (ISH) examination. Seven days after ON crush, thoracotomy was performed. The animals were perfused through the heart with heparin saline followed by $4 \%$ paraformaldehyde, including diethypyrocarbonate (DEPC) for ISH. Eyes with ON segments up to the optic chiasm were post-fixed overnight and transferred to a $30 \%$ sucrose solution including DEPC for ISH overnight at $4^{\circ} \mathrm{C}$. Frozen sections $(15 \mu \mathrm{m})$ were cut longitudinally on a cryostat, thaw mounted onto coated glass slides and stored at $-80^{\circ} \mathrm{C}$ until further use.

Digoxygenin-labeled sense and antisense RNA probes were generated. The serial number (NM-011095) and cDNA array of the PirB gene were obtained from GenBank. The probe was designed with Primer 3 software (Whitehead Institute for Biomedical Research, Cambridge, MA, USA). The common probe was 5'-TATTGTCTCTATAAAAAGGGAAATCCACG AAATCC-3'; 5'-AGGAACATGACACTGCACTGTATCTC ACATAGTCA-3'; 5'-TGTGTACACCACTCTACTGGAGGCC AATACAGATG-3'. Cryostat sections $(15 \mu \mathrm{m})$ were mounted on Superfrost-Plus slides. Sections were post-fixed in 4\% paraformaldehyde and PBS, acetylated in $0.1 \mathrm{M}$ triethanolamine and $0.25 \%$ acetic anhydride, and permeabilized for $20 \mathrm{~min}$ in $1 \%$ Triton X-100 and PBS. Hybridization was performed overnight in $5 \mathrm{X} 300 \mathrm{mM} \mathrm{NaCl}, 30 \mathrm{mM}$ sodium citrate, $\mathrm{pH} 7.0$ (SSC) buffer containing 50\% formamide and 2\% blocking reagent at $68^{\circ} \mathrm{C}$. Two rigorous washes were performed in $0.2 \mathrm{X}$ SSC at the same temperature for $1 \mathrm{~h}$, and signals were detected with alkaline phosphatase-coupled anti-digoxygenin antibodies using SABC as color reaction substrates.

Statistical analysis. Data were analyzed by one-way analysis of variance to determine statistical significance using Origin ver. 6.0 software (OriginLab Corp., Northampton, MA, USA).

\section{Results}

Expression of PirB mRNA by in situ hybridization. Brown staining indicated positive expression of PirB mRNA. Expression of PirB mRNA was noted in the retinal ganglion cells (RGCs) of mice (Fig. 1).

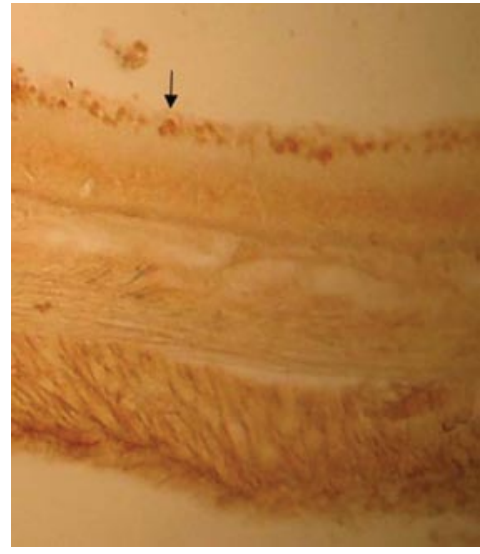

Figure 1. Expression of PirB in retinal ganglion cells of control mice (ISH). Scale bar, $40 \mu \mathrm{m}$.

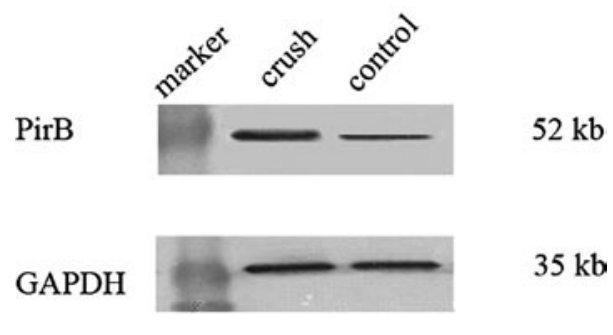

Figure 2. Expression of PirB protein in retinal ganglion cells increased after optic nerve crush (lane 2) compared to control mice (lane 3).

Expression of PirB protein after optic nerve crush by Western blotting. Expression of PirB protein was noted in the normal control mice (Fig. 2, lane 3); however, expression of PirB protein was significantly increased in the experimental group with the crushed ON (Fig. 2, lane 2). The difference in PirB protein expression between the experimental and the control groups was significant $(\mathrm{P}<0.01)$.

\section{Discussion}

In mammals, the Nogo-66 receptor $(\mathrm{NgR})$ has been proposed to play an crucial role in the mediation of axonal growth inhibition (9). $\mathrm{NgR}$ is a glycosylphosphatidylinositol (GPI)linked, leucine-rich repeat (LRR) protein that binds to the 66 amino acid (aa) loop between the two C-terminal hydrophobic domains of Nogo (termed Nogo-66), and transduces Nogo66-mediated axonal inhibition (6).

Kim et al (10) observed significant CST fiber sprouting in young Nogo-A/B ${ }^{-/}$mice compared to wild-type or Nogo-A/ $\mathrm{B}^{+/}$mice. Simonen et al (11) noted moderate CST fiber regeneration in Nogo- $\mathrm{A}^{-/}$mice. However, Zheng et al (12) found no significant regeneration in either Nogo- $\mathrm{A} / \mathrm{B}^{-/}$or $\mathrm{Nogo}-\mathrm{A} / \mathrm{B} / \mathrm{C}^{-1-}$ line mice compared to the wild-type. The varying degrees of regenerative capacity after Nogo elimination were attributed to differences in the genetic backgrounds of the mice used in the experiments. Our previous research found that the knockdown of Nogo-A or Nogo-A/B/C effectively improved the axonal regeneration of the $\mathrm{ON}$ after crush $(13,14)$.

Kim et al (15) showed that NgR deficiency improved raphespinal and rubrospinal axon regeneration, but not 
the regeneration of corticospinal neurons. Zheng et al (12) also failed to find any improvement in $\mathrm{NgR}$ knockout mice regarding corticospinal regeneration compared to wild-type controls. In short, although the knockout of $\mathrm{NgR}$ has not been shown to improve the regeneration of CST axons after dorsal hemisection, some regeneration of raphespinal and rubrospinal tracts after spinal cord injury has been reported.

The paired immunoglobulin-like receptor-A (PirA) and PirB have recently been identified in mice on the basis of their homology with the human $\mathrm{Fc}$ a receptor ( $\mathrm{Fc}$ aR). PirA and PirB share sequence homology with a gene family including human Fc aR and killer inhibitory receptors (KIR), mouse gp49, bovine $\mathrm{Fc}$ receptor for $\mathrm{IgG}$ ( $\mathrm{Fc} \mathrm{gR})$, and the recently identified human Ig-like transcripts (ILT)/leukocyte Ig-like receptors (LIR)/monocyte/macrophage Ig-like receptors (MIR). The Pira and Pirb genes are located on mouse chromosome 7 in a region syntenic with the human chromosome $19 \mathrm{q} 13$ region that contains the Fc aR, KIR and ILT/LIR/MIR genes.

The PirB protein, encoded by the PirB gene, has a typical uncharged transmembrane region and a long cytoplasmic tail with multiple candidate immunoreceptor tyrosine-based inhibitory motifs (ITIMs). Recent studies have demonstrated the inhibitory function of the two most membrane-distal ITIM units in the PirB cytoplasmic region. PirB inhibitory function is mediated through ITIM recruitment of the protein tyrosine phosphatase SHP-1. Although PirB appears to be a more important receptor for substrate inhibition than $\mathrm{NgR}$, inactivation of either PirB or NgR alone is sufficient to block the acute growth-cone collapse caused by the addition of myelin inhibitors.

In the immune system, PirB acts through Shp-1 and Shp-2 phosphatases to inhibit signals that may lead to the inappropriate and dangerous activation of immune cells against normal, healthy cells. PirB is thought to regulate cytoskeletal dynamics, cell motility and adhesion, acting downstream of Src family kinases to modulate integrin signaling, Catt signaling and kinase cascades (16). Atwal et al (8) reported that, in neurons, PirB also recruits both Shp-1 and Shp-2. Thus, PirB may have analogous functions in restricting the response of neurons to activity-dependent or Catt-dependent signaling, thereby limiting the aspects of synaptic plasticity. It is possible that cellular mechanisms that normally regulate and limit the selective strengthening or stabilization of synapses, the formation of new synapses, or even the outgrowth of new neurites after perturbations of sensory input, are altered without functional PirB (16).

We detected the expression of PirB by ISH and investigated the variable level after ON crush by Western blotting. The expression of PirB was subsequently found to be located in RGCs in the retina, and there was increased expression of PirB protein after ON injury. A significant difference was found between the experimental and normal control groups. The above results confirm that the knockout of $\mathrm{NgR}$ in the retina may enhance axonal regeneration after $\mathrm{ON}$ crush. We conclude that increased expression of PirB is associated with the inhibition of axonal regeneration after $\mathrm{ON}$ injury. Inhibition of PirB expression before injury may abrogate the effect of the inhibition of axonal regeneration.

In conclusion, these results suggest that PirB may be associated with the inhibition of axonal regeneration after injury. It is our hope that the data presented here will help to promote ongoing efforts to further elucidate the role of molecular mediators of optic nerve outgrowth inhibition.

\section{Acknowledgements}

We would like to thank Professor Peter Lin of the Baylor College of Medicine (USA) and Professor Gu Zhao-Bin of Gifu University (Japan) for their help in accomplishing our research. This study was supported by grants from the Natural Science Foundation of Heilongjiang Province (no. D2007-80), the Science Foundation of the Education Ministry of China (20092307120003) and the Postdoctoral Science Foundation of China (20080430137,200902418).

\section{References}

1. Chen MS, Huber AB, van der Haar ME, Frank M, Schnell L, Spillmann AA, Christ F and Schwab ME: Nogo-A is a myelinassociated neurite outgrowth inhibitor and an antigen for monoclonal antibody IN-1. Nature 403: 434-439, 2000.

2. GrandPre T, Nakamura F, Vartanian T and Strittmatter SM: Identification of the Nogo inhibitor of axon regeneration as a Reticulon protein. Nature 403: 439-444, 2000.

3. Mukhopadhyay G, Doherty P, Walsh FS, Crocker PR and Filbin MT: A novel role for myelin-associated glycoprotein as an inhibitor of axonal regeneration. Neuron 13: 757-767, 1993.

4. McKerracher L, David S, Jackson DL, Kottis V, Dunn RJ and Braun PE: Identification of myelin-associated glycoprotein as a major myelin-derived inhibitor of neurite growth. Neuron 13: 805-811, 1994.

5. Wang KC, Koprivica V, Kim JA, Sivasankaran R, Guo Y, Neve RL and He Z: Oligodendrocyte-myelin glycoprotein is a Nogo receptor ligand that inhibits neurite outgrowth. Nature 417: 941-944, 2002.

6. Fournier AE, GrandPre T and Strittmatter SM: Identification of a receptor mediating Nogo-66 inhibition of axonal regeneration. Nature 409: 341-346, 2001.

7. Zheng B, Ho C, Li S, Keirstead H, Steward O and Tessier-Lavigne $\mathrm{M}$ : Lack of enhanced spinal regeneration in Nogo-deficient mice. Neuron 38: 213-224, 2003.

8. Atwal JK, Parkinston-Gosse J, Syken J, Stawicki S, Wu Y, Shatz $\mathrm{C}$ and Tessier-Lavigne M: PirB is a functional receptor for myelin inhibitors of axonal regeneration. Science 322: 967-971, 2008.

9. Liu BP, Cafferty WB, Budel SO and Strittmatter SM: Extracellular regulators of axonal growth in the adult central nervous system. Philos Trans R Soc Lond B Biol Sci 361: 1593-1610, 2006.

10. Kim JE, Li S, GrandPre T, Qiu D and Strittmatter SM: Axon regeneration in young adult mice lacking Nogo-A/B. Neuron 38: 187-199, 2003.

11. Simonen M, Pedersen V, Weinmann O, Schnell L, Buss A, Leder-mann B, Christ F, Sansig G, Vander-Putten $\mathrm{H}$ and Schwab ME: Systemic deletion of the myelin-associated outgrowth inhibitor Nogo-A improves regenerative and plastic responses after spinal cord injury. Neuron 38: 201-111, 2003.

12. Zheng B, Atwal J, Ho C, Case L, He XL, Garcia KC, Steward O and Tessier-Lavigne M: Genetic deletion of the Nogo receptor does not reduce neurite inhibition in vitro or promote corticospinal tract regeneration in vivo. Proc Natl Acad Sci USA 102: 1205-1210, 2005.

13. Su Y, Wang F, Zhao SG, Liu P, Cui H and Teng Y: Axonal regeneration of retinal ganglion cells after optic nerve crush: experimental of Nogo-A knockout mice. Natl Med J China 86: 3409-3413, 2006.

14. Su Y, Wang F, Zhao SG, Liu P, Teng Y and Cui H: Axonal regeneration of optic nerve after crush in Nogo-A/B/C knockout mice. Mol Vis 14: 268-273, 2008.

15. Kim JE, Liu BP, Park JH and Strittmatter SM: Nogo-66 receptor prevents raphespinal and rubrospinal axon regeneration and limits functional recovery from spinal cord injury. Neuron 44: 439-451, 2004.

16. Pereira S, Zhang H, Takai T and Clifford AL: The inhibitory receptor PIR-B negatively regulates neutrophil and macrophage integrin signaling. J Immunol 173: 5757-5765, 2004. 